\title{
Hybrid microspheres and percolated monoliths synthesized via Pickering emulsion co-polymerization stabilized by in situ surface-modified silica nanoparticles
}

\author{
B. Fouconnier ${ }^{*}$, F. López-Serrano ${ }^{2}$, R. I. Puente Lee ${ }^{2}$, J. E. Terrazas-Rodríguez ${ }^{1}$, \\ A. Román-Guerrero ${ }^{3}$, M. C. Barrera ${ }^{1}$, J. Escobar ${ }^{4}$ \\ ${ }^{1}$ Facultad de Ciencias Químicas, Universidad Veracruzana, Av. Universidad Km. 7.5, Col. Santa Isabel, 96538 \\ Coatzacoalcos, México \\ ${ }^{2}$ Departamento de Ingeniería Química, Facultad de Química, Universidad Nacional Autónoma de México, 04510 CDMX, \\ México \\ ${ }^{3}$ Departamento de Biotecnología, Universidad Autónoma Metropolitana Unidad Iztapalapa, San Rafael Atlixco 186, Col. \\ Vicentina, Iztapalapa, 09340 CDMX, México \\ ${ }^{4}$ Instituto Mexicano del Petróleo, Eje Central Lázaro Cárdenas 152, San Bartolo Atepehuacan, G.A. Madero, 07730 \\ CDMX, México
}

Received 28 August 2020; accepted in revised form 9 December 2020

\begin{abstract}
The Pickering emulsion polymerization of styrene (St), divinylbenzene (DVB) as a crosslinking agent, and sodium 4-vinyl benzene sulfonate (VBS) used for in situ surface-modification of silica nanoparticles (SNps) was investigated. At $1.0 \mathrm{wt} \%$ DVB, amphiphilic SNps with hydrophobic patches were formed, further self-assembling into copolymer-SNps clusters occurred. Subsequently, these clusters grow by monomer swelling to finally lead to the formation of core-shell polymer microspheres. Unlike the hydrophilic patchy SNps, at 2.0 and $3.0 \mathrm{wt} \%$ DVB, surface-patterned SNps with higher effective hydrophobicity do not self-assemble in the water phase but rather lead to the formation of monoliths. The polymerization mechanisms related to the formation of polymer silica-coated microspheres hybrid-materials, or percolated monoliths with bi-continuous porosity, formed by interfacially jammed emulsion gel (bijels) templates, are discussed herein.
\end{abstract}

Keywords: nanocomposites, Pickering emulsion polymerization, mechanisms, bijel, monolith

\section{Introduction}

In the past few decades, high academic and industrial interests have been dedicated to Pickering emulsion polymerizations, as they represent a straightforward method for preparing inorganic/organic microspheres [1-3]. These hybrid nanomaterials present large specific areas and extraordinary properties due to the combination of the nascent compounds' individual characteristics. They are used in many applications such as separation, sensing, catalysis, electrophoretic ink, and light scattering [4-8], among others. However, for their successful applications, functional polymer microspheres with specific size and morphology have to be designed and fabricated. In Pickering emulsion polymerizations, the microsphere size and morphology depend on the interactions between the inorganic nanoparticles (Nps) and the growing oligomers [9], as they act on the nucleation and coagulation processes [10-11]. In this sense, homogeneous coagulative nucleation has been associated with the formation of submicronic polymer particles, representing the dominating mechanism 
when a hydrophilic initiator is used [12]. However, a good affinity between the Nps and the polymer matrix is required to obtain successful hybrid particle formation with a well-defined core-shell structure [13]. This 'likeness' character can be fulfilled by means of favorable interactions between the polymer and the inorganic particles, where inorganic Nps are usually surface modified or functionalized by grafting $[10,14]$.

Therefore, tailoring the surface structure of polymer microspheres is of major interest due to their potential applications; their morphology and particle size are responsible for their functionality, and therefore they become the main variables to control. These characteristics are also influenced and controlled by the inorganic Nps' surface nature. Consequently, when the Nps' surface contains reactive groups on their surface, the microspheres' properties may be difficult to control due to fluctuations at the inorganic stabilizer's surface while the reaction of polymerization occurs $[8,11,15,16]$. Other technological properties sought like good mechanical and chemical stability, suitable thermal properties, and swelling of polystyrene microspheres are required [17].

Yin et al. [15] used vinyl benzene sulfonate (VBS) to prepare surface-functionalized polystyrene microspheres using titanium nanoparticles. They showed that the bifunctional VBS monomer not only favored the accumulation of titania Nps on the microsphere surface via electrostatic forces, but also polystyrene microspheres were synthesized via a coagulative nucleation mechanism controlled by the VBS concentration. This is why at low VBS concentration, the polymer hybrid microspheres exhibited small particle sizes with a narrower particle size distribution, whereas larger hybrid microspheres with a polydisperse particle size distribution were achieved when VBS concentration was increased. This phenomenon was attributed to the prolonged nucleation period, induced by the presence of free sulfonic groups in the polymer chains, which increased the titania Nps solubility in water.

On the other hand, divinylbenzene (DVB) is commonly used as a crosslinking agent that improves the microspheres' properties, especially in suspension and emulsion polymerizations [18]. For instance, during the synthesis of highly porous polymer materials and high internal phase emulsion (HIPE) polymerizations, a crosslinking agent and Nps have been used as reinforcing agents [19]. Nonetheless, in Pickering-HIPE polymerizations, the interest is generally focused on the Nps, functioning solely as emulsion stabilizing agents, instead of understanding their polymerization contribution in the continuous phase. Moreover, Chen et al. [8] and Yin et al. [9] have reported the use of DVB in the preparation of submicronic polystyrene microspheres in Pickering emulsions, even when those emulsions contained low polymer internal-phase weight fractions. Besides, the DVB role as a crosslinking agent on the size and morphology of the core-shell microspheres, this compound has not been thoroughly discussed.

Otherwise, bicontinuous interfacially jammed emulsion gels (bijels) are a class of soft materials, which are a resource for a great variety of technological applications [20]. These materials were first predicted by numerical simulation [21] and first experimentally obtained in 2007 by Herzig et al. [22] by performing the thermal quenching of pairs of liquid mixtures. These authors reported that the formation of bijels usually involves the interfacial capture of two immiscible liquids, withstanding spinodal decomposition, being mechanically stabilized, in a non-equilibrium configuration, by a jammed monolayer of colloidal particles at their interface [21, 22], where polymeric bicontinuous morphologies are formed by means of segregation and nanoparticles jamming at the polymer blends interphase during separation [2324]. In addition to interfacial jamming, if colloidal gelation occurs in one of the polymer blend phases, it could also yield bicontinuous structures [25].

Other paths to obtain bijels, that do not involve thermal quenching have been described by the solvent transference that induces phase separation (STrIPS) to obtain different and complex bijel morphologies [26-30], and more recently, some works have reported that bijels can be formed simply by shaking two immiscible fluids [31, 32].

Thus, the aims of this work were to prepare co(StDVB) polymer hybrid materials, via Pickering emulsion polymerization, using sodium 4-vinylbenzenesulfonate (VBS), in order to achieve the in situ formation of surface-modified silica nanoparticles. The patchy SNps' amphiphilic character upon DVB concentrations and the polymerization mechanisms that led to silica-coated polymer microspheres and bi-continuous hybrid macroporous materials were investigated. Moreover, a facile approach for creating bi-continuous macroporous materials through the formation of bijel templates upon undergoing 
polymerization containing 2 and $3 \mathrm{wt} \% \mathrm{DVB}$ is presented.

\section{Experimental}

\subsection{Materials}

Ludox ${ }^{\circledR}$ (CL-X colloidal of silica, CAS number: 7631-86-9) silica nanoparticles (SNps) coated by a thin alumina layer and positively charged (size $\left.12 \mathrm{~nm}, 30 \mathrm{wt} \%, 230 \mathrm{~m}^{2} \cdot \mathrm{g}^{-1}, \mathrm{pH}=4.5\right)[33,34]$, ammonium hydroxide (AH, CAS number: 1336-21-6), and ammonium chloride (AC, CAS number: 1212502-9) were purchased to Sigma-Aldrich (SigmaAldrich S.A. de C.V., Toluca, Mexico). Styrene (St; CAS number: 100-42-5), divinylbenzene (DVB; CAS number: 1321-74-0) as a crosslinking agent, sodium 4-vinylbenzenesulfonate (VBS, CAS number: 2695-37-6) as SNps' surface modifying agent, sodium hydroxide ( $\mathrm{NaOH}, \mathrm{CAS}$ number 1310-73-2), acetic acid (AA, CAS number: 64-19-7), and ammonium persulfate (APS, CAS number: 7727-54-0) were purchased from Merck KGaA (Mexico City, Mexico).

Sodium acetate (SA, CAS number: 127-09-3) was of the brand J.T. Baker ${ }^{\circledR}$ (Mexico City, Mexico). Deionized water was used in all the polymerizations.

\subsection{St-DVB co-polymerization}

Prior to polymerization, $60 \mathrm{ml}$ of monomer mixtures (Table 1) were washed three times using $60 \mathrm{ml}$ of $\mathrm{NaOH}$ solutions at $10 \mathrm{wt} \%$ in order to remove the inhibitor, followed by washing three times with deionized water. The monomer mixtures were then stored under refrigeration until used. Coarse $\mathrm{O} / \mathrm{W}$ emulsions were prepared at a mass dispersed fraction of 0.21 by mixing $50 \mathrm{~g}$ of monomer mixtures $(1.0,2.0$, and $3.0 \mathrm{wt} \% \mathrm{DVB}$ ) with $200 \mathrm{~g}$ of water containing $62.5 \mathrm{mg}$ of VBS and $20 \mathrm{~g}$ of SNps (Ludox $\mathrm{CL}^{\circledR}$ ) using an Ultra Turrax T25 homogenizer (IKAWerke Works Inc., Wilmington, NC, USA) at $15000 \mathrm{rpm}$ during $10 \mathrm{~min}$. A $500 \mathrm{ml}$ double-walled reactor, equipped with an external recirculating bath, a condenser, and a four-bladed metal propeller fitted in a four-necked reactor vessel, was used. Previous to the emulsion ingredients, $33.76 \mathrm{~g}$ of acid acetic + sodium acetate buffer solution ( $2 \mathrm{M}$ and $\mathrm{pH} 5$ ) were added to the reactor. The emulsions were kept under stirring at $500 \mathrm{rpm}$ for $45 \mathrm{~min}$ and purged with nitrogen for $15 \mathrm{~min}$. Finally, emulsion polymerizations were initiated after the addition of $3 \mathrm{ml}$ of APS aqueous solution ( $2 \mathrm{wt} \%$ relative to monomers content) into the reaction vessel. Reactions were carried out at $80 \pm 1^{\circ} \mathrm{C}$. Table 1 summarizes the formulations used. All experiments were performed at least by triplicate.

\subsection{VBS surface-modified SNps, emulsions and hybrid materials' characterization}

Zeta potential ( $\zeta$-potential) of SNps and VBS suspensions (Table 1) was determined in dilute suspensions at $1 \mathrm{wt} \%$ in the range of $\mathrm{pH}$ values from 4 to 9, at $25^{\circ} \mathrm{C}$ using a Zetasizer NanoZS2000 (Malvern Instruments Ltd., Malvern, Worcestershire, UK). The suspensions were placed under stirring for $1 \mathrm{~h}$ until the adsorption equilibrium onto SNps surface was reached, previous to $\zeta$-potential and $\mathrm{pH}$ measurements in agreement with Zhao et al. [35].

Structuration of hybrid materials during emulsion copolymerization was done by evaluating the monomer droplet evolution during the polymerization process by withdrawing emulsion samples from the reactor at $5,10,20$, and 30 min reaction times until the reaction time reached (90 $\mathrm{min})$. Samples were placed in vials that contained $150 \mu \mathrm{l}$ of hydroquinone solution ( $5 \mathrm{wt} \%$ ) in order to stop the polymerization reaction. One droplet of each emulsion sample was gently poured between microscope glasses, and the structures were observed in an Olympus BX45 microscope (Olympus Optical Co., Ltd., Japan) with a magnification of $100 \times$, coupled to a digital camera Moticam 2300 (Motic Group Co., Ltd., Xiamen, China).

On the other hand, polymer microspheres and 2-D polymer monolith structures were observed by Transmission Electron Microscopy (TEM) in a JEOL

Table 1. Formulations of the $\mathrm{O} / \mathrm{W}$ emulsions containing a dispersed mass fraction of 0.21 and stabilized by surface-modified SNps.

\begin{tabular}{|c|c|c|c|c|c|c|}
\hline \multirow[b]{2}{*}{ Experiment } & \multirow{2}{*}{$\begin{array}{c}\text { Aqueous phase } \\
{[\mathrm{g}]}\end{array}$} & \multicolumn{2}{|c|}{ Surface modified SNps } & \multicolumn{2}{|c|}{ Monomer mixture } & \multirow{2}{*}{$\begin{array}{c}\text { Initiator } \\
\text { APS } \\
\text { [g] }\end{array}$} \\
\hline & & $\begin{array}{l}\text { SNps } \\
\text { [g] }\end{array}$ & $\begin{array}{c}\text { VBS } \\
{[g]}\end{array}$ & $\begin{array}{l}\text { St } \\
{[g]}\end{array}$ & $\begin{array}{c}\text { DVB } \\
\text { [g] }\end{array}$ & \\
\hline 1 & 236.76 & 6.0 & 0.0625 & 50.0 & 0.505 & 1.010 \\
\hline 2 & 236.76 & 6.0 & 0.0625 & 50.0 & 1.020 & 1.020 \\
\hline 3 & 236.76 & 6.0 & 0.0625 & 50.0 & 1.546 & 1.030 \\
\hline
\end{tabular}

${ }^{*}$ Aqueous phase means refers to the water and buffer solution contents in emulsion. 
transmission electron microscope model 2010 (JEOL, Japan) at $20 \mathrm{kV}$ acceleration voltage and magnification of $3000 \times$. Briefly, the polymer microsphere suspension was dispersed in isopropanol, a droplet of the resultant mixture was deposited on a carbon film supported on a copper grid and air-dried at room temperature $\left(25^{\circ} \mathrm{C}\right)$. Regarding 2-D polymer monoliths, samples were previously dried overnight at $50^{\circ} \mathrm{C}$ and ground into powder (marble mortar), then placed on a carbon film to take TEM images. Samples were also cut into about $0.3 \mathrm{~cm}$ in length and mounted on an aluminum SEM specimen stub for analysis.

\section{Results and discussion}

\subsection{Characterization of the VBS surface-modified silica nanoparticles}

The SNps' surface activity was evaluated by means of $\zeta$-potential because the available literature has reported that interactions between nanoparticles in polymer hybrid structures play an important role in controlling the physicochemical characteristics of final products. SNps in LudoxCL ${ }^{\circledR}$ consist of nanoparticles of silica-coated with alumina, which provides to SNps a positive surface charge $(\sim 44 \mathrm{mV})$ [36]. Nevertheless, when VBS was added to the nanoparticle suspension, in order to improve the affinity from SNps to St polymer by acting during the polymerization like bond former via its vinyl groups, the $\zeta$-potential decreased to $\sim 35 \mathrm{mV}$. This reduction is associated with the electrostatic interactions between the anionic sulfonate groups of VBS and the positive moieties of SNps, causing the adsorption of the former onto the surface due to electrostatic interactions $[8,15]$.

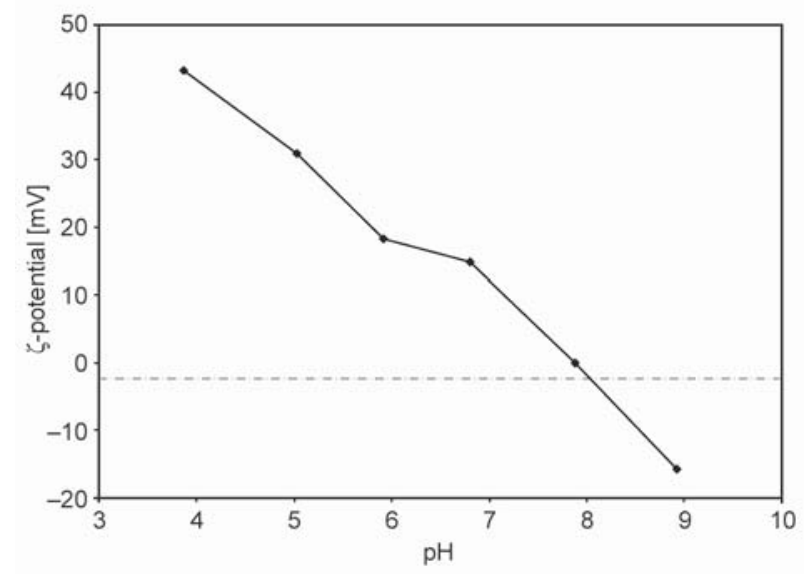

Figure 1. $\zeta$-potential profile of the VBS surface-modified SNps.
Figure 1 shows the $\zeta$-potential for surface-modified $\mathrm{SNps}$ with VBS as a function of the $\mathrm{pH}$. Here it can be seen that these nanoparticles displayed positive surface charges at $\mathrm{pH}$ between 3.0 and 7.0, showing an isoelectric point at $\mathrm{pH} 8.0$, with neutral surface charge $(\sim 0 \mathrm{mV})$ and negative $\zeta$-potential values at higher $\mathrm{pH}$ values $(-15 \mathrm{mV}$ at $\mathrm{pH} 9.0)$. It is worth mentioning that Koroleva et al. [36] reported a similar $\zeta$-potential profile for Ludox $\mathrm{CL}^{\circledR}$ silica suspension that differ from our results in the magnitude of the surface charge, associated with the absence of negative-charged VBS adsorbed on SNps surface. Because SNps are $\mathrm{pH}$-dependent, due to the amphoteric nature of aluminol groups [37], their surface activity may be tuned by $\mathrm{pH}$ changes or by the VBS adsorption [38], becoming an important variable that influences the polymerization reaction yields.

In this sense, preliminary studies (not shown) exhibited that during polymerization reactions, the $\mathrm{pH}$ decreased below 3.5 due to initiator decomposition that yields the formation of hydronium ions [39], causing aluminum species to get dissolved, inducing the SNps destabilization [40]. For this reason, the $\mathrm{pH}$ in the reaction media was maintained above 3.5.

In the $\mathrm{pH}$ interval 3.5 to 5 , the surface-modified SNps exhibit a $\zeta$-potential value higher than $+30 \mathrm{mV}$; therefore, they are weakly flocculated and can be considered as a stable colloidal dispersion with translucent aspect [41].

The number of VBS anions totally adsorbed per unit nanoparticle surface $\left(\rho_{\mathrm{VBS}}\right)$ can be determined by Equation (1) [39, 42]:

$\rho_{\mathrm{VBS}}=\frac{m_{\mathrm{VBS}} N_{\mathrm{A}}}{M_{\mathrm{VBS}} S_{\mathrm{BET}} m_{\mathrm{SNps}}}$

where $m_{\mathrm{VBS}}$ is the mass of VBS, $N_{\mathrm{A}}$ is Avogadro's number, $M_{\mathrm{VBS}}$ is the VBS molecular weight, $S_{\mathrm{BET}}$ is the specific surface area of the dried SNps and $m_{\mathrm{SNps}}$ is the mass of SNps in the aqueous phase. Plugging numbers, the density ( $\rho_{\mathrm{VBS}}$ ) of VBS anions adsorbed onto the SNps is about $0.132 \mathrm{~nm}^{-2}$ (i.e., $60 \mathrm{VBS}$ anions per silica nanoparticle).

\subsection{Preparation of poly(St-co-DVB)/silica nanocomposite particles}

In Experiment 1, the polymerization yields the formation of polymer microspheres coated by SNps, and these polymer nanoparticles are exhibited by the 

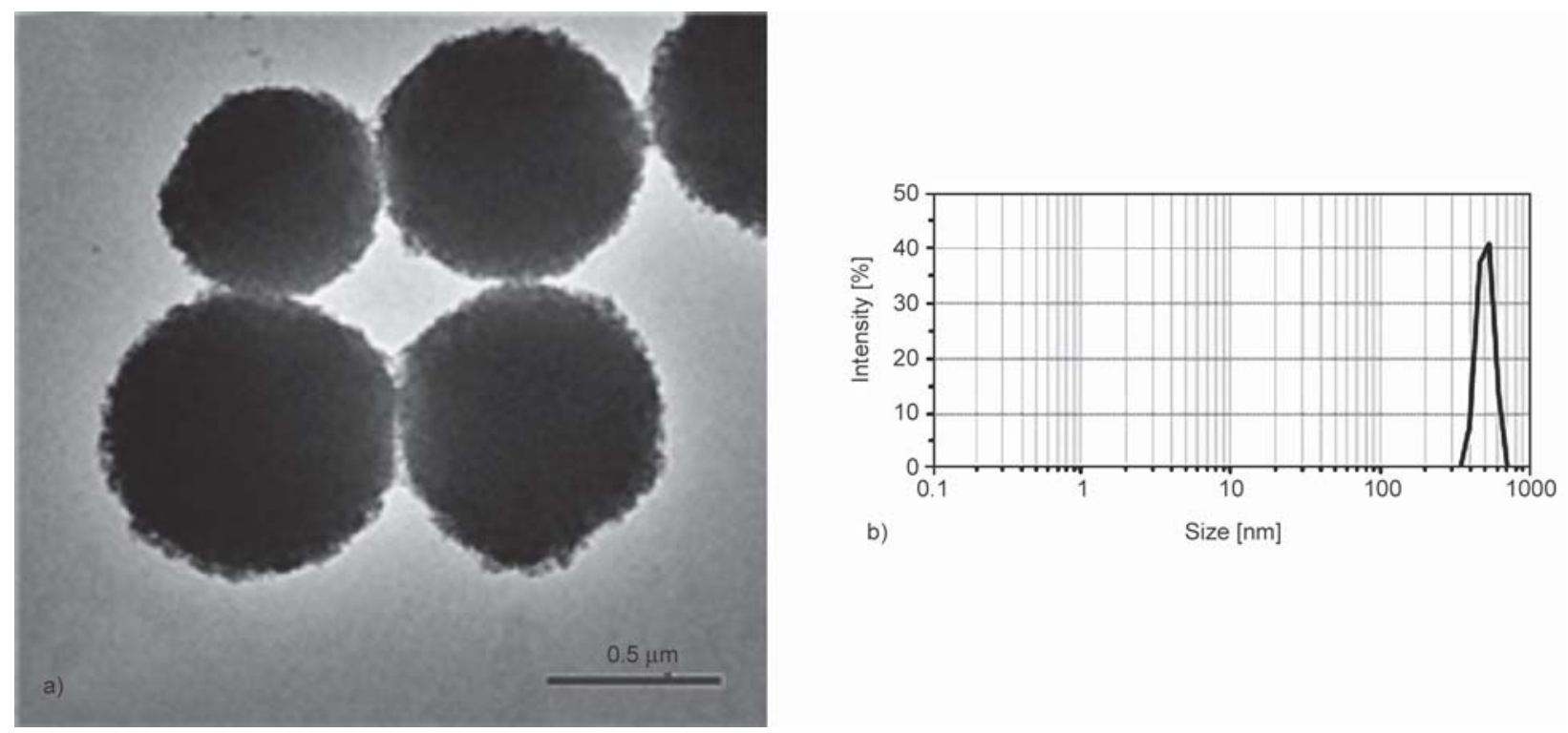

Figure 2. a) TEM image of polymer microspheres obtained at $1 \mathrm{wt} \% \mathrm{DVB}$ and b) their size distribution.

TEM image of Figure 2a. In Figure 2b, it can be observed that the microspheres have an average hydrodynamic diameter of $500 \mathrm{~nm}$ and present a narrow and monomodal particle size distribution.

In this emulsion polymerization process, once the hydrophilic initiator was injected into the reactor, the free radicals reacted with St and DVB monomers, both being slightly soluble in the aqueous phase, also with VBS monomer adsorbed onto the SNps. Oligomeric sulfates formed from St and DVB molecules are surface-active and will adsorb onto the surfacemodified SNps by electrostatic attraction via their negative moieties [43]. Consequently, it can be considered that most of the growing oligomers are attached to surface-modified SNps [15]. These oligomers are either formed in the continuous phase or by the ones attached to the surface-modified SNps since the beginning, the latter corresponding to VBS. Therefore, at the very beginning of the reaction, each oligomer is absorbed isolated onto the SNps surface, and the surface excess increases upon oligomers adsorption; consequently, lateral interactions between polymer chains occur that lead to the formation of hydrophobic patches (also called hemimicelles) onto the SNps' surface [44]. These lateral interactions are fundamental for depicting a heterogeneous coagulative nucleation process. Indeed, the hydrophobic tethered chains grow onto the $\mathrm{SNp}$ surface and then reach a critical length that will force the polymer chains to form hydrophobic polymer patches onto the SNps. Thus, the SNps exhibit a slight improvement of their hydrophobicity that induces their selfassembly into polymer latex-SNp clusters [35]. In such a case, they can be considered as amphiphilic particles [45-47] that aggregate into nascent nuclei, where the polymer hydrophobic chains entangle each other to reduce their contact with water, forming a hydrophobic polymer core [35], coated by a hydrophilic SNp shell. In turn, these nuclei will then grow via monomer swelling [8], provided by the droplet reservoirs, to finally give rise to core-shell microspheres. During polymerization, the in situ functionalization of the microspheres is provided by the accumulation of surface-modified SNps or other tethered surface-modified SNps on their surface.

In Pickering emulsions, the homogeneous coagulative nucleation mechanism is the dominant process when the hydrophilic initiator is separated from the oil phase, and this mechanism usually leads to the formation of microspheres with core-shell structure [48-50]. Contrarily, in this work, we postulate a different mechanism, considering that the oligomers grow and coagulate onto the surface-modified SNps $[8,9]$. Consequently, we propose, as Shin et al. [10], that the dominant process involved in the Pickering emulsions is represented by heterogeneous coagulative nucleation [16, 51-54]. Besides, it is noteworthy that the oligomer tethered chains which coagulate onto the surface-modified SNp surface, water being a poor solvent for them, form pinned micelles or hydrophobic patches, giving the SNps an amphiphile character [55-56]. These amphiphile primary particles will then self-assemble as micelles do, into spherical polymer-SNp clusters to give rise to the formation of secondary particles that will then grow by monomer swelling. Therefore, the Pickering emulsion 


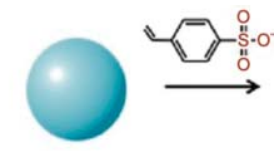

a)

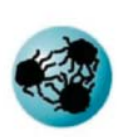

d)

Figure 3. Scheme describing the polymerization steps occurring in Experiment 1. a) Positive SNps, b) surface modified SNps, c) tethered SNps, d) SNps with hydrophobic patches, e) copolymer-SNps clusters, f) core-shell polymer microspheres.

polymerization involves four steps: initiation, primary particle formation by heterogeneous coagulative nucleation, self-assembly of primary particles into secondary particles, and growth. For better clarity, these polymerization mechanisms are schematically described in Figure 3.

\subsection{Preparation of bi-continuous macroporous monoliths}

In Experiments 2 and 3, monolith-type structures were surprisingly obtained instead of microspheres, as reported by Chen et al. [8] and Yin et al. [15]. At the end of the polymerization, all the water phase (i.e. $79 \mathrm{wt} \%)$ has been incorporated within a solid-like polymer structure (i.e. $21 \% \mathrm{wt} \%$ ). TEM images of the monoliths were taken after being dried overnight at $50^{\circ} \mathrm{C}$ and are exhibited in Figure 4. Their morphologies resemble crumbled sheets of paper or aluminum foil. Monoliths are usually prepared by using HIPE with an internal phase volume greater than $74 \%$ in order to

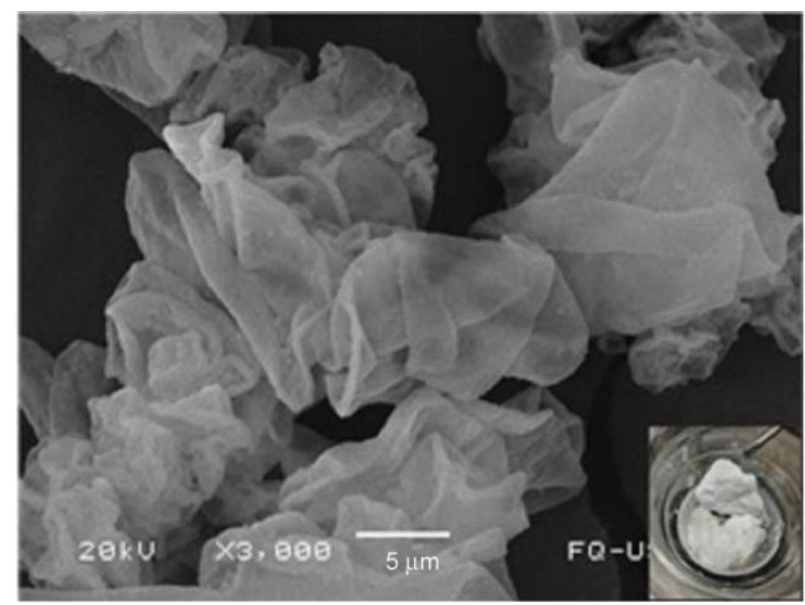

a) get a highly porous void structure through the polymerization of the external emulsion phase. The use of surfactant-free HIPE has been reported because surface-modified nanoparticles can offer high stability to the emulsion against coalescence without using a high amount of surfactant, which is difficult and costly to remove [57].

Consequently, it can be concluded that the polymerization mechanism schemes for Experiment 1 and Experiments 2 and 3 differ regarding the amount of DVB that interferes in the wettability properties of the surface-modified SNps. A phase inversion of the original $\mathrm{O} / \mathrm{W}$ emulsions has to occur in order to give rise to the formation of monoliths at the end of the reactions. Thus, emphasis should be placed on the heterogeneous coagulative process and specifically on the formation of the primary particles that also behave akin to amphiphiles [58-60], but, instead of self-assembling into polymer-SNp clusters in the aqueous phase, they adsorb and polymerize at the water/interface during polymerization $[61,62]$, leading to the formation of a percolated monolith in the Pickering emulsions.

Polymer tethered nanoparticles can self-assemble into a large range of anisotropic structures such as spherical, sheet-like, cylindrical, lamellar, and bi-continuous morphologies [63]. Self-assembled structure formations are driven by a microphase separation between the inorganic particles and the grafted polymer chains. The structure is determined by a subtle energy balance between an enthalpic gain that occurs when the inorganic particles approach each other and an entropic gain due to the distribution of the polymer chains around the particles [59, 64-66]. Moreover, the

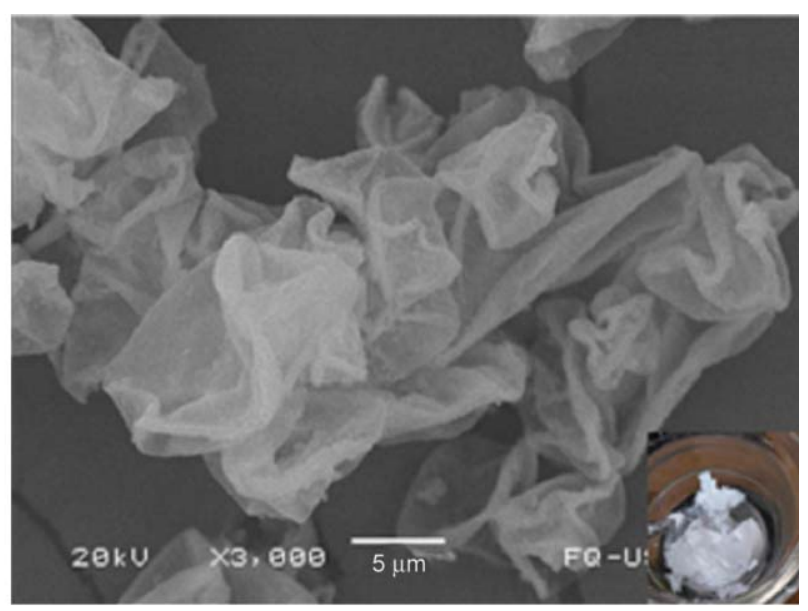

b)

Figure 4. SEM image of percolated monolith obtained with (a) $2 \mathrm{wt} \% \mathrm{DVB}$ and (b) $3 \mathrm{wt} \% \mathrm{DVB}$. The insets show the monoliths extracted from the reactor. 
core-core attractions and the unfavorable polymercore interactions depend on the nanoparticle size and the polymer corona architecture characterized by the grafting density, the length, and flexibility of the polymer chains, among others [42].

Bedrov et al. [63] studied the aggregation of hydrophobic fullerenes tethered by hydrophilic polyethylene oxide (POE) chains in aqueous solutions. They showed that a high density of carbon was responsible for attractive interactions among fullerenes, which induced their aggregation. The tethered fullerenes did not separate in microphases. However, the molecular dynamic simulations showed that self-assembly depends upon the fullerene-fullerene attractive interactions, POE-POE and POE-fullerene interactions, and steric repulsion between POE chains.

In this study, the preparation of the hybrid materials is based on the one-pot synthesis. Here, there is no control of the number and size of the tethered chains

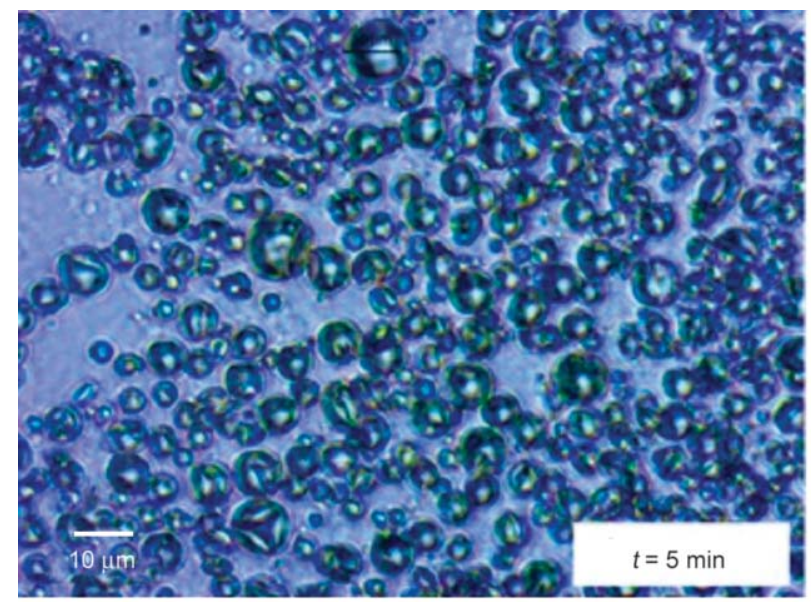

a)

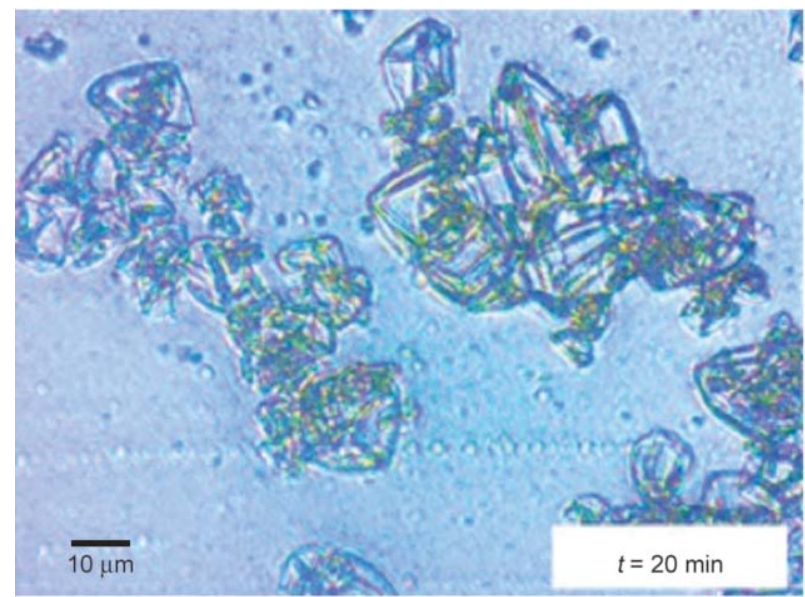

c) since the tethered surface-modified SNps form in situ, and therefore, their properties vary as the reaction occurs [8]. Figure 5 depicts a series of microscopic images at different reaction times for Experiment 2. The polymerization evolution stages for Experiment 3 are similar and thus, are not shown. In Figure 5, it can be observed that spherical monomer droplets are initially dispersed in the aqueous phase. Then, after $10 \mathrm{~min}$ of reaction, the droplets are deformed. After $20 \mathrm{~min}$, the droplet interface is progressively covered by multi-patch particle agglomerates already covered by surface-modified SNps since the emulsion preparation. Particles with effective hydrophobicity agglomerate at the droplet interface [67], and both hydrophobic particle agglomerates and hydrophilic surface-modified SNps confer the droplets a non-spherical shape accentuated by deformation due to monomer swelling during the reaction. Finally, after $30 \mathrm{~min}$, the monomer droplets are disappearing,

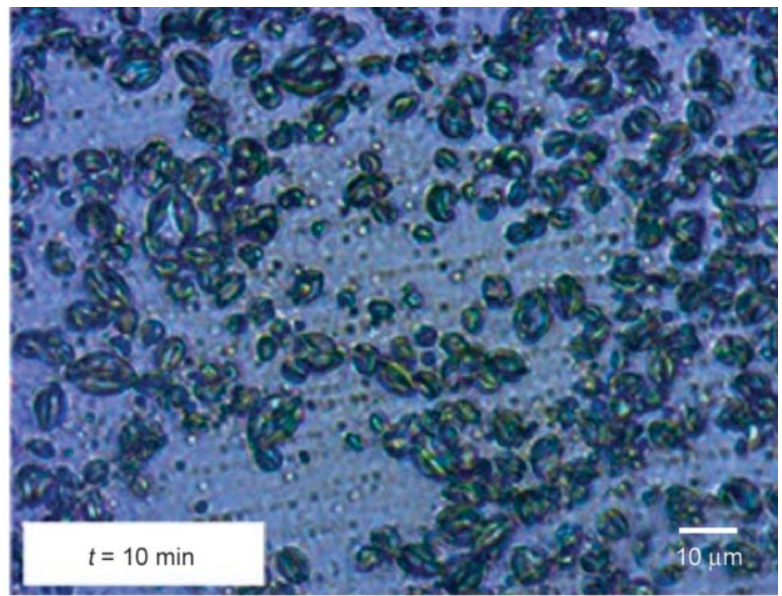

b)

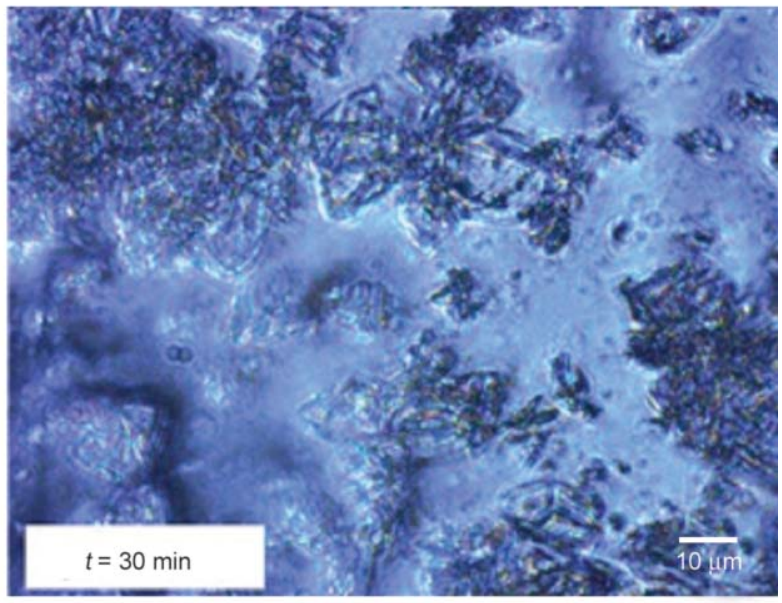

d)

Figure 5. Optical microscopy images taken during Experiment 2, representing the evolution of the emulsion droplets during 30 min of polymerization. Similar images are obtained in Experiment 3. a) After 5 min, the droplets are spherical and polydisperse. b) After 10 min, the droplets are highly deformed. c) Patchy SNps absorb and jam at the droplets' interface d) Emulsion destabilization process occurs and an interconnected network of SNps is being formed. 
and an interconnected SNp network is being formed while the monomer droplets disappear.

This effect clearly indicates that tethered formed particles, adsorbed at the droplet interface [68, 69], behave akin to a surfactant, considering the uncovered nanoparticle surface as the hydrophilic patch and the nanoparticle surface covered by the polymer chains as the hydrophobic sites. Moreover, anisotropy is assigned to nanoparticles because they are functionalized with a small number of tethers at specific locations onto the nanoparticle surface. Consequently, due to their amphiphilic character, these nanoparticles can self-assemble into different structures depending on their hydrophobic/hydrophilic balance [70]. This statement can be corroborated by TEM images of amphiphilic SNps formed in Experiments 2 and 3,

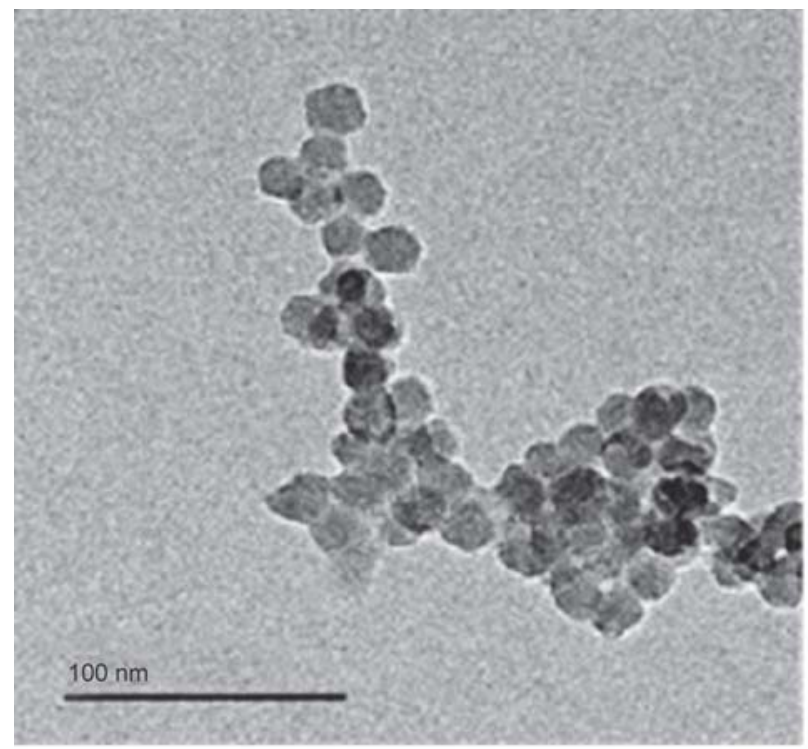

a)

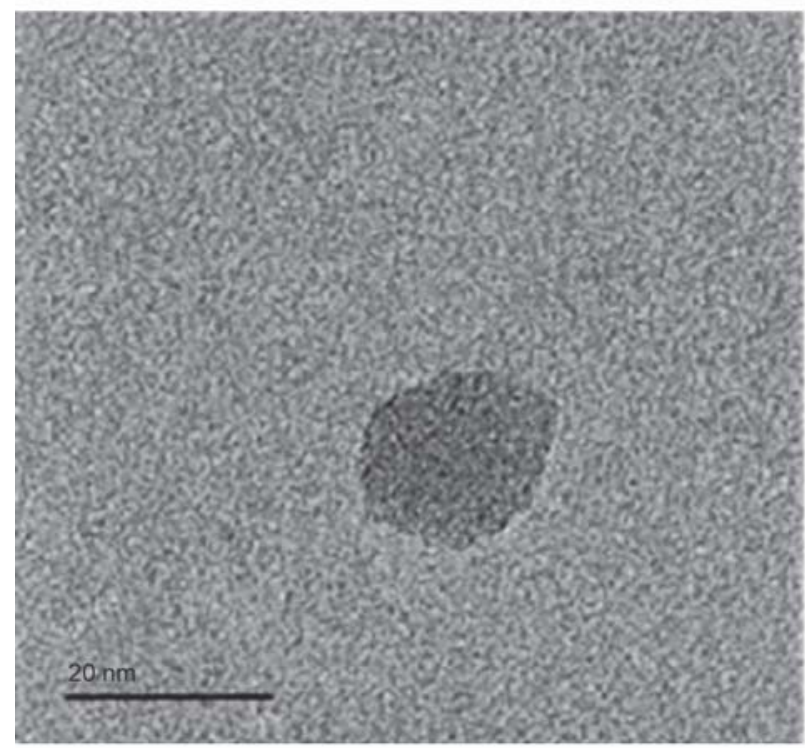

c) after 20 min of reaction. In Figure 6 aggregation of SNps is observed. The SNps are not spherical and exhibit a higher diameter than their original one $(12 \mathrm{~nm})$. Moreover, on the surface of a few of them, puffiness can be observed, which can be attributed to the polymerization of hydrophobic patches. Finally, it is noteworthy that in Figures 4 and 7, polymer particles can be observed on the surface of the monolith structures. These particles probably originated from the polymerization which occurred on the surface of amphiphilic particles but were not incorporated into the polymer structure.

On the other hand, Asai et al. [55] established a quantitative analogy between polymer grafted nanoparticles and patchy ones. They showed that the nanoparticle assembly could be understood through geometric

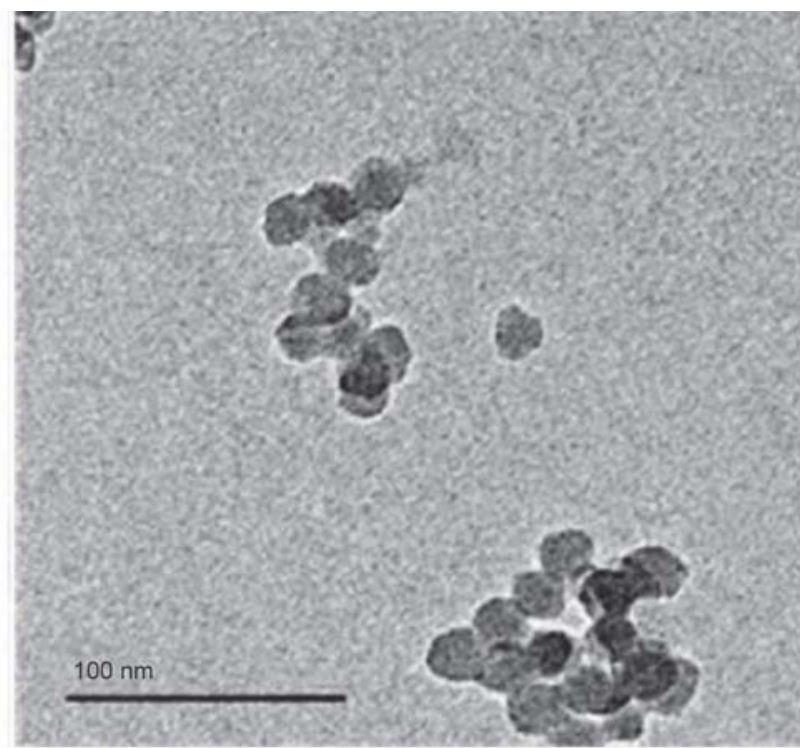

b)

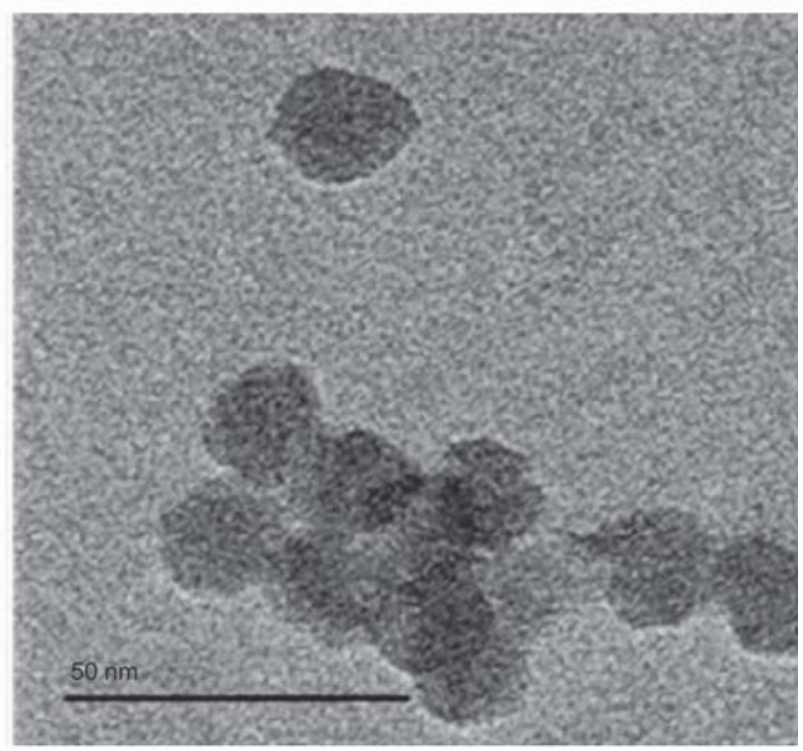

d)

Figure 6. TEM images of amphiphilic SNps obtained after 20 min of reaction. a) Experiment 2, b), c) and d) Experiment 3. 
considerations of single patch models, in the same spirit of the geometric packing parameter of surfactants. They quantified the nanoparticle surface, occluded by the grafted spheres, and analyzed the cluster distribution of the covered areas as a function of the tethered chain number $f$. This was calculated at different values of the size ratio $(\alpha)$ of the grafted spheres to the nanoparticles' radii. For all size ratios $\alpha$, the number of clusters passed through a maximum and yielded high values at low $\alpha$ ratios. In contrast, the maximum values significantly decreased as $\alpha$ increased. They also observed that at low graft density, and especially at $\alpha \geq 0.3$, the grafted particles behaved like Janus particles, with one attractive patch and another repulsive patch, whereas at $\alpha<0.3$, the nanoparticles were covered by multiple clusters which can self-assemble into different structures. As a result of their analysis, they showed that the grafted polymer nanoparticles could self-assemble into four morphologies (clump \& dispersed, string, sheet, and aggregates), delimited by zones onto a phase diagram. The morphology zones were defined as a function of the tether number $\mathrm{f}$ and the grafted chain length.

Differently, Choueiri et al. [56] studied the surface patterning of nanoparticles with polymer patches and reported that polymer brushes could form hydrophobic patches depending upon solvent quality. The hydrophobic patch formation and structure depended on the nanoparticle diameter, the polymer chain length, and the grafting density. More specifically, the number of patches per nanoparticle was determined by the ratio of the nanoparticle diameter $(D)$ to the polymer chain radius $(R)$, whereas the patch dimension was governed by the grafting density. They also showed that the polymer segregation is likely to occur when nanoparticles have high surface curvature, leading to the breaking up of polymer chains into pinned micelles onto the nanoparticle surface.

In all Experiments, the density of VBS anions adsorbed onto the SNps is low due to the low concentration of VBS used in the emulsions. Thus, solely a fraction of VBS anions react with the monomers dissolved in the aqueous phase, and the first stage polymerization process likely results in the formation of sparsely tethered silica particles. Based on these considerations, at $1.0 \mathrm{wt} \% \mathrm{DVB}$, the polymer chains grow onto the nanoparticle surface by polymerization until the tethered nanoparticles become insoluble in water and self-assemble into pseudo-micelle aggregates. Therefore, the amphiphilic particles [71] have a limited improvement in hydrophobicity and exhibit low attachment energy at the monomer/water interface. The tether chains formed onto the SNps can interact laterally to form hydrophobic patches, which in turn orientate and entangle due to Van der Waals interactions during the particles' agglomeration, to give rise to the formation of a polymer core covered by SNps in contact with the water phase.

In contrast, at higher DVB concentrations, the tethered nanoparticles do not self-assemble into micelle aggregates and adsorb at the water/oil droplet interface [35]. This observation implies that the crosslinking agent inevitably interferes in the oligomer chains' growing process, modifying the number, length, and flexibility of the tethered chains. Indeed, the tether chains grow in the aqueous phase in a sparse fashion, and the intramolecular crosslinking is promoted. Thus, it can be inferred that hard patchy units formed onto the SNps at specific locations and with fixed patchiness [71]. Furthermore, due to the intramolecular crosslinking, a reduction in the hydrodynamic radius, and the apparent average molecular weight (between crosslinks) is expected [72]. It has been reported [50] that, at low grafting density and for $\alpha$ value smaller than 0.3 , the surface is covered by multiple clusters. Similarly, Choueri et al. [56] reported that, at constant grafting density and constant nanoparticle diameter, reduction of the chain radius led to a larger number of patches per nanoparticle. Therefore, it is expected that SNps with multiple hydrophobic patches are formed in Experiments 2 and 3. Moreover, a poor-quality solvent and crosslinking increase result in a diminution of the interpenetration of the polymer chains attached to the silica nanoparticle, accompanied by shrinkage of the tether length. Both effects induce weaker hydrophobic interactions between the nanoparticle tethered chains and impart pronounced amphiphilic character to the nanoparticles. Finally, it can be inferred that upon DVB addition, nanoparticles with multiple hard patch units were formed in water during polymerization and these patchy nanoparticles, due to their amphiphile nature, were likely to adsorb at the water-oil interface [61]. In addition, adsorbed amphiphile molecules at a fluid interface assemble and lead to high deformation of the droplet interface [73].

Actually, bi-continuous emulsions are inter-penetrated structures of two immiscible liquids that share a layer of colloidal nanoparticles collocated at the interface [31]. Generally, bi-continuous interfacial 
jammed emulsion gels are formed via spinodal decomposition, but Huang et al. [31] reported the preparation of jammed emulsions via homogenization by using hydrophilic nanoparticles and functional polymers. Bijels stabilization was attributed to the use of a mixture of polymers with different molecular weights, which confer hydrophilic and hydrophobic character to the nanoparticles, that could be wetted by both water and the oil phases equally. Thus, Bijels stabilization was obtained by those hydrophilic and hydrophobic nanoparticles.

During polymerization, multiple polymer patch SNps (primary particles), formed in the continuous water phase, adsorb at the water/oil interface where their hydrophobicity rises due to polymerization as their molecular weight increases [31]. Similarly, the hydrophilic VBS surface-modified SNps anchored therein can polymerize, also exhibiting a molecular weight increase. Therefore, at the interface, the formation of patchy SNps with different molecular weights occurs, and the hydrophobic character of these amphiphilic particles increases and their interfacial density induces a change of their radius of curvature, which finally yields phase emulsion inversion: the internal phase changes from monomer phase to waterrich phase. We conclude that the bijel stabilized by patchy SNps is formed during the process of the emulsion phase inversion, where neither monomer nor water is the internal phase. The bijel is characterized as a soft solid [30], and it is noteworthy that at this polymerization step, the system is highly viscous and characterized by the jamming of the patchy SNps at the water/oil interface. An interconnected network is formed as the reaction proceeds to complete

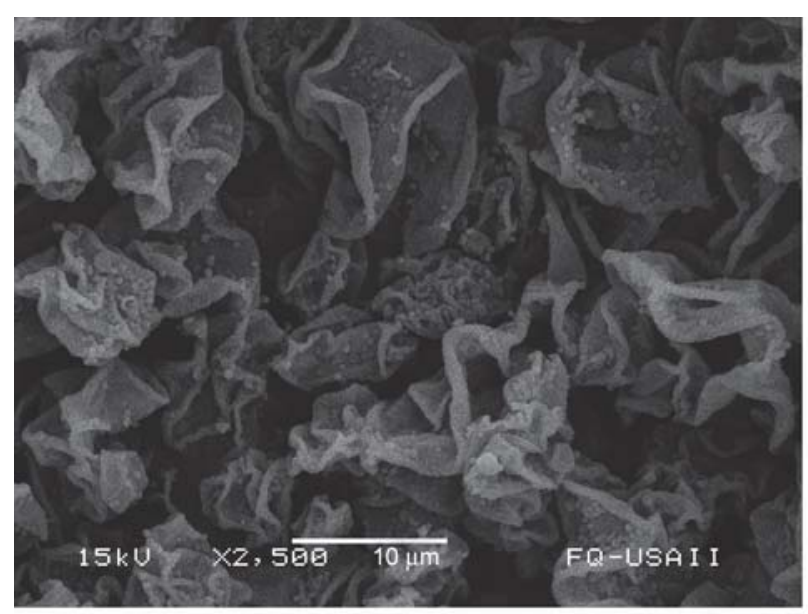

a)

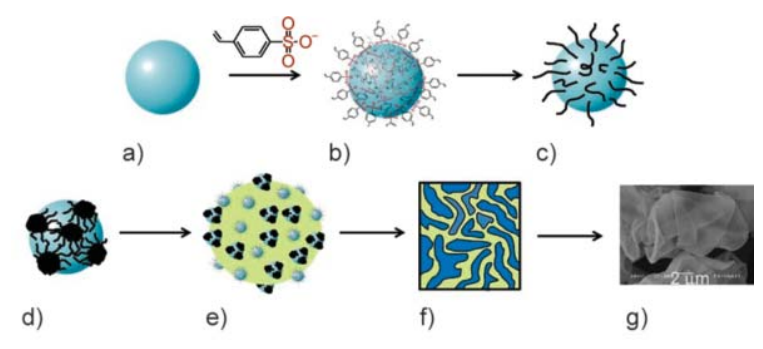

Figure 8. Scheme describing the polymerization steps occurring in Experiments 2 and 3. a) Positive SNps, b) surface modified SNps, c) tethered SNps, d) surface-patterned SNps, e) adsorption of surface-patterned SNps at the monomer droplet interface, f) bijel, g) bicontinous macroporous monolith.

monomers' conversion due to crosslinking. Thus, the final hybrid material is then characterized by a monolith with bi-continuous porosity, which differs from monoliths prepared via Pickering-HIPE polymerizations. SEM images of monoliths obtained in Experiments 2 and 3 are exhibited in Figure 7. Actually, the pictures reveal macroporous structures composed of polymer layers distributed throughout the materials.

For clarity, a scheme describing the polymerization steps is presented in Figure 8.

These results are not entirely unlike the ones reported by Lin et al. [74], where they prepared an ultrathin composite organic-inorganic membrane. This membrane was obtained by the self-assembly of functionalized nanoparticles at the water/toluene interface, and the nanoparticles layer was stabilized by the crosslinking of Cadmium selenide (CdSe) nanoparticle organic ligands. They also reported that the membrane crumpled morphology resulted from the shear stress during manipulation.

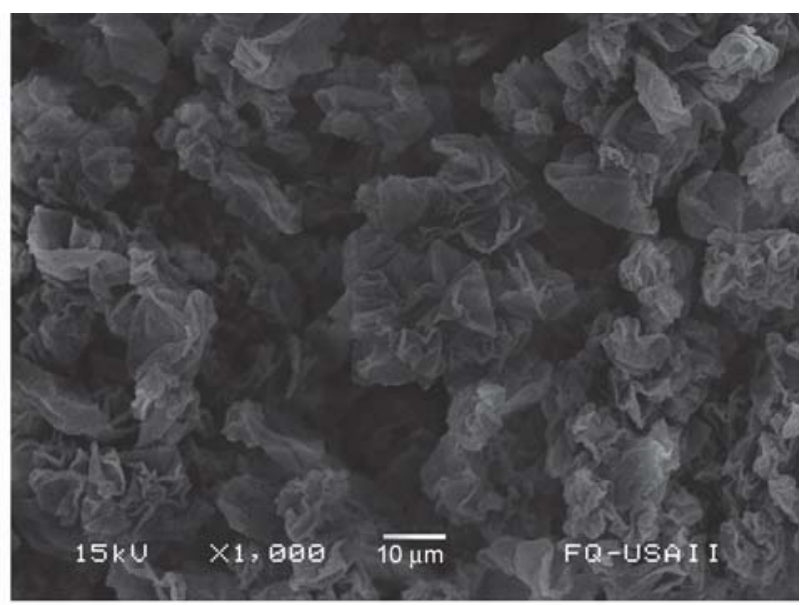

b)

Figure 7. SEM image of percolated monolith obtained with (a) $2 \mathrm{wt} \%$ DVB and (b) $3 \mathrm{wt} \%$. 


\section{Conclusions}

In summary, it is clear that the in situ functionalization of SNps yields enhanced affinity to the hydrophobic monomer phase because the VBS anions interact on one side with the SNps, via electrostatic interactions, and on the other side with monomers via the vinyl group. The polymerization occurs onto the surface-modified SNps via the vinyl group due to the high stability of the surface-modified SNp colloidal dispersion. After initiation, primary particles are formed via heterogeneous coagulative nucleation, as the oligomer tethered chains coagulate onto the $\mathrm{SNp}$ surface due to poor solvent quality. This heterogeneous coagulative nucleation is the key process in the Pickering emulsion polymerizations, which induces the formation of SNps or patchy hybrid SNps, depending upon DVB concentration. These hybrid SNps, due to their amphiphilic nature, can self-assemble into anisotropic structures. At $1 \mathrm{wt} \% \mathrm{DVB}$, the primary SNps self-assemble into secondary particles characterized by polymer latex-SNps clusters, which will then grow to lead the formation of silicapoly(St-DVB) hybrid microspheres. However, at 2 and $3 \mathrm{wt} \% \mathrm{DVB}$, the polymerization process is intriguing. The primary SNps are surface-patterned with various hydrophobic copolymer patches and adsorb at the water/oil interface, where they accumulate and polymerize with hydrophilic VBS surface-modified SNps anchored at the interface during the emulsion preparation. The hydrophobicity of both patchy and surface-modified SNps will increase upon polymerization, exhibiting various degrees of hydrophobicity. Finally, the increased hydrophobicity, of the amphiphilic hybrid SNPs and their density at the interface, modifies the radius of curvature of the anchored surface-modified SNps. This induces the inversion of the oil/water emulsion, thus leading to the formation of a bi-continuous structured-liquid stabilized by the hybrid SNps at the interface. The bijel finally results in the formation of a percolated monolith with bi-continuous porosity until the complete conversion of monomers. To the best of our knowledge, the formation of bi-continuous macroporous polymer monoliths in Pickering emulsions has not been reported. Therefore, the findings of this work represent valuable information for designing new hybrid materials and a step forward in the understanding of mechanisms in Pickering emulsion polymerizations. We also foresee diverse applications of those percolated monoliths as filter membranes, contaminant removal, and polymer-supported catalysis.

\section{Acknowledgements}

This study was financially supported by CONACyT grant CB-2014-240160. FLS gratefully acknowledges support by UNAM, DGAPA (PAPIIT IN114018).

\section{References}

[1] Yin D., Zhang Q., Yin C., Jia Y., Zhang H.: Effect of particle coverage on morphology of $\mathrm{SiO}_{2}$-covered polymer microspheres by Pickering emulsion polymerization. Colloids and Surfaces A: Physicochemical and Engineering Aspects, 367, 70-75 (2010).

https://doi.org/10.1016/j.colsurfa.2010.06.021

[2] Azhar U., Huo Z., Yaqub R., Xu A., Zhang S., Geng B.: Non-crosslinked fluorinated copolymer particles stabilized Pickering high internal phase emulsion for fabrication of porous polymer monoliths. Polymer, 172, 160-169 (2019).

https://doi.org/10.1016/j.polymer.2019.03.068

[3] Tu S., Zhu C., Zhang L., Wang H., Du Q.: Pore structure of macroporous polymers using polystyrene/silica composite particles as Pickering stabilizers. Langmuir, 32, 13159-13166 (2016).

https://doi.org/10.1021/acs.langmuir.6b03285

[4] Gao J., Huang X., Xue H., Tang L., Li R. K. Y.: Facile preparation of hybrid microspheres for super-hydrophobic coating and oil-water separation. Chemical Engineering Journal, 326, 443-453 (2017).

https://doi.org/10.1016/j.cej.2017.05.175

[5] Gu C., Cui Y., Wan L., Sheng E., Shim J-J., Huang J.: Synthesis of the porous $\mathrm{NiO} / \mathrm{SnO}_{2}$ microspheres and microcubes and their enhanced formaldehyde gas sensing performance. Sensors and Actuators B: Chemical, 241, 298-307 (2017). https://doi.org/10.1016/j.snb.2016.10.060

[6] Li Y., Wang Y., Ambreen J., Yang C., Ngai T.: Synthesis of structured hollow microspheres with sandwich-like hybrid shell of $\mathrm{RGO} / \mathrm{Pd} / \mathrm{m}-\mathrm{SiO}_{2}$ for highly efficient catalysis. Colloids and Surfaces A: Physicochemical and Engineering Aspects, 577, 129-137 (2019).

https://doi.org/10.1016/j.colsurfa.2019.05.059

[7] Li J., Deng L., Xing J., Dong A., Li X.: Preparation and characterization of $\mathrm{TiO}_{2}$-cationic hybrid nanoparticles as electrophoretic particles. Applied Surface Science, 258, 3152-3157 (2012).

https://doi.org/10.1016/j.apsusc.2011.11.053

[8] Chen Z., Qin Z., Wang H., Du Q.: Tailoring surface structure of polymer nanospheres in Pickering emulsion polymerization. Journal of Colloid and Interface Science, 401, 80-87 (2013).

https://doi.org/10.1016/j.jcis.2013.03.045

[9] Yin G., Zheng Z., Wang H., Du Q., Zhang H.: Preparation of graphene oxide coated polystyrene microspheres by Pickering emulsion polymerization. Journal of Colloid and Interface Science, 394, 192-198 (2013).

https://doi.org/10.1016/j.jcis.2012.11.024 
[10] Shin J-H., Park J-W., Kim H-J.: Clay-polystyrene nanocomposite from Pickering emulsion polymerization stabilized by vinylsilane-functionalized montmorillonite platelets. Applied Clay Science, 182, 105288/1105288/12 (2019).

https://doi.org/10.1016/j.clay.2019.105288

[11] Fouconnier B., Terrazas-Rodríguez J. E., F. LópezSerrano F.: Monitoring styrene Pickering $\mathrm{SiO}_{2}$-supported emulsion polymerization kinetics by Raman spectroscopy: Elucidating mechanisms interpreting the silanol/phenyl $\pi$-interactions. Journal of Macromolecular Science Part A, 54, 509-515 (2017).

https://doi.org/10.1080/10601325.2017.1320758

[12] Monégier du Sorbier Q., Aimable A., Pagnoux C.: Influence of the electrostatic interactions in a Pickering emulsion polymerization for the synthesis of silicapolystyrene hybrid nanoparticles. Journal of Colloid and Interface Science, 448, 306-314 (2015).

https://doi.org/10.1016/j.jcis.2015.02.017

[13] Cao-Luu N-H., Pham Q-T., Yao Z-H., Wang F-M., Chern C-S.: Synthesis and characterization of $\operatorname{poly}(\mathrm{N}$ isopropylacrylamide-co-acrylamide) mesoglobule coresilica shell nanoparticles. Journal of Colloid and Interface Science, 536, 536-547 (2019).

https://doi.org/10.1016/j.jcis.2018.10.091

[14] Zhou M. J., Zhou S. Z., Pang X. C., Li K. R., Qiao X. G.: Preparation of superparamagnetic $\gamma-\mathrm{Fe}_{2} \mathrm{O}_{3} @ \mathrm{LS} @ P S$ composite latex particles through Pickering miniemulsion polymerization. Colloids and Surfaces A: Physicochemical and Engineering Aspects, 585, 124040/1124040/6 (2020).

https://doi.org/10.1016/j.colsurfa.2019.124040

[15] Yin G., Zheng Z., Wang H., Du Q.: Slightly surfacefunctionalized polystyrene microspheres prepared via Pickering emulsion polymerization using for electrophoretic displays. Journal of Colloid and Interface Science, 361, 456-464 (2011).

https://doi.org/10.1016/j.jcis.2011.06.017

[16] Lotierzo A., Bon S. A. F.: A mechanistic investigation of Pickering emulsion polymerization. Polymer Chemistry, 8, 5100-5111 (2017).

https://doi.org/10.1039/C7PY00308K

[17] Liu Q., Wang L., Xiao A.: Research progress in macroporous styrene-divinylbenzene co-polymer microspheres. Designed Monomers and Polymers, 10, 405 423 (2007).

https://doi.org/10.1163/156855507781833620

[18] Rahmatpour A., Goodarzi N., Moazzez M.: A novel route for synthesis of cross-linked polystyrene copolymer beads with tunable porosity using guar and xanthan gums from bioresources as alternative synthetic suspension stabilizers. Designed Monomers and Polymers, 21, 116-129 (2018).

https://doi.org/10.1080/15685551.2018.1489698
[19] Li T., Liu H., Zeng L., Yang S., Li Z., Zhang J., Zhou X.: Macroporous magnetic poly(styrene-divinylbenzene) nanocomposites prepared viamagnetite nanoparticlesstabilized high internal phase emulsions. Journal of Materials Chemistry, 21, 12865-12872 (2011). https://doi.org/10.1039/C1JM10799B

[20] Ngai T., Bon S. A. F.: Particle-stabilized emulsions and colloids formation and applications. Royal Society of Chemistry, Cambridge (2015).

[21] Stratford K., Adhikari R., Pagonabarraga I., Desplat J-C., Cates M. E.: Colloidal jamming at interfaces: A route to fluid-bicontinuous gels. Science, 309, 2198-2201 (2005). https://doi.org/10.1126/science.1116589

[22] Herzig E. M., White K. A., Schofield A. B., Poon W. C. K., Clegg P. S.: Bicontinuous emulsions stabilized solely by colloidal particles. Nature Materials, 6, 966971 (2007). https://doi.org/10.1038/nmat2055

[23] Gam S., Corlu A., Chung H-J., Ohno K., Hore M. J. A., Composto R. J.: A jamming morphology map of polymer blend nanocomposite films. Soft Matter, 7, 72627268 (2011). https://doi.org/10.1039/C1SM05619K

[24] Chung H-J., Kim J., Ohno K., Composto R. J.: Controlling the location of nanoparticles in polymer blends by tuning the length and end group of polymer brushes. ACS Macro Letters, 1, 252-256 (2012). https://doi.org/10.1021/mz200068p

[25] Li L., Miesch C., Sudeep P. K., Balazs A. C., Emrick T., Russell T. P., Hayward R. C.: Kinetically trapped cocontinuous polymer morphologies through intraphase gelation of nanoparticles. Nano Letters, 11, 1997-2003 (2011).

https://doi.org/10.1021/nl200366z

[26] Haase M. F., Stebe K. J., Lee D.: Continuous fabrication of hierarchical and asymmetric bijel microparticles, fibers, and membranes by solvent transfer-induced phase separation (STRIPS). Advanced Materials, 27, 7065-7071 (2015). https://doi.org/10.1002/adma.201503509

[27] Haase M. F., Sharifi-Mood N., Lee D., Stebe K. J.: In situ mechanical testing of nanostructured bijel fibers. ACS Nano, 10, 6338-6344 (2016).

https://doi.org/10.1021/acsnano.6b02660

[28] Haase M. F., Jeon H., Hough N., Kim J. H., Stebe K. J., Lee D.: Multifunctional nanocomposite hollow fiber membranes by solvent transfer induced phase separation. Nature Communications, 8, 1234/1-1234/7 (2017). https://doi.org/10.1038/s41467-017-01409-3

[29] Boakye-Ansah S., Schwenger M. S., Haase M. F.: Designing bijels formed by solvent transfer induced phase separation with functional nanoparticles. Soft Matter, 15, 3379-3388 (2019). https://doi.org/10.1039/C9SM00289H 
[30] Kinkead B., Malone R., Smith G., Pandey A., Trifkovic M.: Bicontinuous intraphase jammed emulsion gels: A new soft material enabling direct isolation of co-continuous hierarchial porous materials. Chemistry of Materials, 31, 7601-7607 (2019).

https://doi.org/10.1021/acs.chemmater.9b02398

[31] Huang C., Forth J., Wang W., Hong K., Smith G. S., Helms B. A., Russell T. P.: Bicontinuous structured liquids with sub-micrometre domains using nanoparticle surfactants. Nature Nanotechnology, 12, 1060-1063 (2017).

https://doi.org/10.1038/nnano.2017.182

[32] Cai D., Clegg P. S., Li T., Rumble K. A., Tavacoli J. W.: Bijels formed by direct mixing. Soft Matter, 13, 48244829 (2017).

https://doi.org/10.1039/C7SM00897J

[33] Viota J. L., Raşa M., Sacanna S., Philipse A. P.: Stability of mixtures of charged silica, silica-alumina, and magnetite colloids. Journal of Colloid and Interface Science, 290, 419-425 (2005).

https://doi.org/10.1016/j.jcis.2005.04.064

[34] Stejskal J., Kratochvíl P., Armes S. P., Lascelles S. F., Riede A., Helmstedt M., Prokeš J., Křivka I.: Polyaniline dispersions. 6 . Stabilization by colloidal silica particles. Macromolecules, 29, 6814-6819 (1996). https://doi.org/10.1021/ma9603903

[35] Zhao Y., Yin G., Zheng Z., Wang H., Du Q.: Preparation of polymer hollow microspheres covered by polymer solid particles via two polymerization steps. Journal of Polymer Science Part A: Polymer Chemistry, 49, 5257 5269 (2011).

https://doi.org/10.1002/pola.25002

[36] Koroleva M., Bidanov D., Yurtov E.: Emulsions stabilized with mixed $\mathrm{SiO}_{2}$ and $\mathrm{Fe}_{3} \mathrm{O}_{4}$ nanoparticles: Mechanisms of stabilization and long-term stability. Physical Chemistry Chemical Physics, 21, 1536-1545 (2019). https://doi.org/10.1039/C8CP05292A

[37] Sposito G.: The environmental chemistry of alumina. Lewis Publishers, Boca Raton (1996).

[38] Li J., Stöver H. D. H.: Pickering emulsion templated layer-by-layer assembly for making microcapsules. Langmuir, 26, 15554-15560 (2010). https://doi.org/10.1021/la1020498

[39] Kolthoff I. M., Miller I. K.: The chemistry of persulfate. I. The kinetics and mechanism of the decomposition of the persulfate ion in aqueous medium. Journal of the American Chemical Society, 73, 3055-3059 (1951). https://doi.org/10.1021/ja01151a024

[40] Schmitt Pauly C., Genix A-C., Alauzun J. G., Sztucki M., Oberdisse J., Mutin P. H.: Surface modification of alumina-coated silica nanoparticles in aqueous sols with phosphonic acids and impact on nanoparticle interactions. Physical Chemistry Chemical Physics, 17, 19173 19182 (2015).

https://doi.org/10.1039/C5CP01925G
[41] Sun D., Kang S., Liu C., Lu Q., Cui L., Hu B.: Effect of zeta potential and particle size on the stability of $\mathrm{SiO}_{2}$ nanospheres as carrier for ultrasound imaging contrast agents. International Journal of Electrochemical Science, 11, 8520-8529 (2016).

https://doi.org/10.20964/2016.10.30

[42] Wang Z., Zheng Z., Liu J., Wu Y., Zhang L.: Tuning the mechanical properties of polymer nanocomposites filled with grafted nanoparticles by varying the grafted chain length and flexibility. Polymers, 8, 270/1-270/20 (2016). https://doi.org/10.3390/polym8090270

[43] Platzer N. A. J.: Polymerization and polycondensation processes. American Chemical Society, Washington (1962).

[44] Howard S. C., Atkin R., Craig V. S. J.: Effect of electrolyte species on the adsorption of a cationic surfactant to silica: The common intersection point. Colloids and Surfaces A: Physicochemical and Engineering Aspects, 347, 109-113 (2009).

https://doi.org/10.1016/j.colsurfa.2009.01.014

[45] Percebom A. M., Moreira Costa L. H.: Formation and assembly of amphiphilic Janus nanoparticles promoted by polymer interactions. Advances in Colloid and Interface Science, 269, 256-269 (2019).

https://doi.org/10.1016/j.cis.2019.05.001

[46] Zahn N., Kickelbick G.: Synthesis and aggregation behavior of hybrid amphiphilic titania Janus nanoparticles via surface-functionalization in Pickering emulsions. Colloids and Surfaces A: Physicochemical and Engineering Aspects, 461, 142-150 (2014). https://doi.org/10.1016/j.colsurfa.2014.07.039

[47] Zhang C., Liu B., Tang C., Liu J., Qu X., Li J., Yang Z.: Large scale synthesis of Janus submicron sized colloids by wet etching anisotropic ones. Chemical Communications, 46, 4610-4612 (2010). https://doi.org/10.1039/C0CC00054J

[48] Ma H., Luo M., Sanyal S., Rege K., Dai L. L.: The onestep Pickering emulsion polymerization route for synthesizing organic-inorganic nanocomposite particles. Materials, 3, 1186-1202 (2010). https://doi.org/10.3390/ma3021186

[49] Zhang W. H., Fan X. D., Tian W., Fan W. W.: Polystyrene/nano- $\mathrm{SiO}_{2}$ composite microspheres fabricated by Pickering emulsion polymerization: Preparation, mechanisms and thermal properties. Express Polymer Letters, 6, 532-542 (2012). https://doi.org/10.3144/expresspolymlett.2012.57

[50] Morgen T. O., Krumova M., Luttikhedde H., Mecking S.: Free-radical dispersion polymerization of ethylene with laponite to polyethylene-clay nanocomposite particles. Macromolecules, 51, 4118-4128 (2018). https://doi.org/10.1021/acs.macromol.8b00440

[51] Colver P. J., Colard C. A. L., Bon S. A. F.: Multilayered nanocomposite polymer colloids using emulsion polymerization stabilized by solid particles. Journal of the American Chemical Society, 130, 16850-16851 (2008). https://doi.org/10.1021/ja807242k 
[52] Sheibat-Othman N., Bourgeat-Lami E.: Use of silica particles for the formation of organic-inorganic particles by surfactant-free emulsion polymerization. Langmuir, 25, 10121-10133 (2009).

https://doi.org/10.1021/la900895z

[53] Thickett S. C., Zetterlund P. B.: Preparation of composite materials by using graphene oxide as a surfactant in $a b$ initio emulsion polymerization systems. ACS Macro Letters, 2, 630-634 (2013). https://doi.org/10.1021/mz400280t

[54] Teixeira R. F. A., McKenzie H. S., Boyd A. A., Bon S. A. F.: Pickering emulsion polymerization using laponite clay as stabilizer to prepare armored 'soft' polymer latexes. Macromolecules, 44, 7415-7422 (2011). https://doi.org/10.1021/ma201691u

[55] Asai M., Cacciuto A., Kumar S. K.: Quantitative analogy between polymer-grafted nanoparticles and patchy particles. Soft Matter, 11, 793-797 (2015). https://doi.org/10.1039/C4SM02295E

[56] Choueiri R. M., Galati E., Thérien-Aubin H., Klinkova A., Larin E. M., Querejeta-Fernández A., Han L., Xin H. L., Gang O., Zhulina E. B., Rubinstein M., Kumacheva E.: Surface patterning of nanoparticles with polymer patches. Nature, 538, 79-83 (2016).

https://doi.org/10.1038/nature19089

[57] Gurevitch I., Silverstein M. S.: Polymerized pickering HIPEs: Effects of synthesis parameters on porous structure. Journal of Polymer Science Part A: Polymer Chemistry, 48, 1516-1525 (2010).

https://doi.org/10.1002/pola.23911

[58] Kumar S. K., Ganesan V., Riggleman R. A.: Perspective: Outstanding theoretical questions in polymer-nanoparticle hybrids. The Journal of Chemical Physics, 147, 020901/1-020901/19 (2017).

https://doi.org/10.1063/1.4990501

[59] Maillard D., Kumar S. K., Rungta A., Benicewicz B. C., Prud'homme R. E.: Polymer-grafted-nanoparticle surfactants. Nano Letters, 11, 4569-4573 (2011). https://doi.org/10.1021/nl202651u

[60] Nie Z., Fava D., Kumacheva E., Zou S., Walker G. C., Rubinstein M.: Self-assembly of metal-polymer analogues of amphiphilic triblock copolymers. Nature Materials, 6, 609-614 (2007).

https://doi.org/10.1038/nmat1954

[61] Rezvantalab H., Shojaei-Zadeh S.: Designing patchy particles for optimum interfacial activity. Physical Chemistry Chemical Physics, 16, 8283-8293 (2014). https://doi.org/10.1039/C3CP55512G

[62] Grzelczak M., Vermant J., Furst E. M., Liz-Marzán L. M.: Directed self-assembly of nanoparticles. ACS Nano, 4, 3591-3605 (2010). https://doi.org/10.1021/nn100869j

[63] Bedrov D., Smith G. D., Li L.: Molecular dynamics simulation study of the role of evenly spaced poly(ethylene oxide) tethers on the aggregation of 660 fullerenes in water. Langmuir, 21, 5251-5255 (2005).

https://doi.org/10.1021/la0504816
[64] Green P. F.: The structure of chain end-grafted nanoparticle/homopolymer nanocomposites. Soft Matter, 7, 7914-7926 (2011). https://doi.org/10.1039/C1SM05076A

[65] Vogiatzis G. G., Theodorou D. N.: Structure of polymer layers grafted to nanoparticles in silica-polystyrene nanocomposites. Macromolecules, 46, 4670-4683 (2013). https://doi.org/10.1021/ma400107q

[66] Lafitte T., Kumar S. K., Panagiotopoulos A. Z.: Selfassembly of polymer-grafted nanoparticles in thin films. Soft Matter, 10, 786-794 (2014). https://doi.org/10.1039/C3SM52328D

[67] Binks B. P., Philip J., Rodrigues J. A.: Inversion of silica-stabilized emulsions induced by particle concentration. Langmuir, 21, 3296-3302 (2005).

https://doi.org/10.1021/la046915z

[68] Ravera F., Ferrari M., Liggieri L., Loglio G., Santini E., Zanobini A.: Liquid-liquid interfacial properties of mixed nanoparticle-surfactant systems. Colloids and Surfaces A: Physicochemical and Engineering Aspects, 323, 99-108 (2008). https://doi.org/10.1016/j.colsurfa.2007.10.017

[69] Fouconnier B., Roman-Guerrero A., Vernon-Carter E. J.: Effect of [CTAB]- $\left[\mathrm{SiO}_{2}\right]$ ratio on the formation and stability of hexadecane/water emulsions in the presence of $\mathrm{NaCl}$. Colloids and Surfaces A: Physicochemical and Engineering Aspects, 400, 10-17 (2012). https://doi.org/10.1016/j.colsurfa.2012.02.035

[70] Jiang S., Chen Q., Tripathy M., Luijten E., Schweizer K. S., Granick S.: Janus particle synthesis and assembly. Advanced Materials, 22, 1060-1071 (2010). https://doi.org/10.1002/adma.200904094

[71] Gârlea I. C., Bianchi E., Capone B., Rovigatti L., Likos C. N.: Hierarchical self-organization of soft patchy nanoparticles into morphologically diverse aggregates. Current Opinion in Colloid and Interface Science, 30, 1-7 (2017). https://doi.org/10.1016/j.cocis.2017.03.008

[72] Wen J., Zhang J., Zhang Y., Yang Y., Zhao H.: Controlled self-assembly of amphiphilic monotailed singlechain nanoparticles. Polymer Chemistry, 5, 4032-4038 (2014). https://doi.org/10.1039/C4PY00100A

[73] Manoharan V. N., Elsesser M. T., Pine D. J.: Dense packing and symmetry in small clusters of microspheres. Science, 301, 483-487 (2003). https://doi.org/10.1126/science.1086189

[74] Lin Y., Skaff H., Böker A., Dinsmore A. D., Emrick T., Russell T. P.: Ultrathin cross-linked nanoparticle membranes. Journal of the American Chemical Society, 125, 12690-12691 (2003). https://doi.org/10.1021/ja036919a 